\title{
Barriers to Evidence-Based Nursing Practice Utilization from the Perspective of Nurse Managers
}

\author{
Doaa F. Ellboudy ${ }^{1}$, Nermin M. Eid ${ }^{2}$, and Zeinab M. Rashad ${ }^{3}$ \\ ${ }^{1}$ Assistant Lecturer in Nursing Administration, ${ }^{2}$ Professor of Nursing Administration, \\ ${ }^{3}$ Lecturer of Nursing Administration, Faculty of Nursing, Menoufia University
}

\begin{abstract}
Evidence-based practice is considered a foundation for the provision of quality care. Nurse managers (NMs) play an important role promoting evidence-based practice (EBP) on clinical units within hospitals. However, there is a dearth of research focused on NMs perspectives about barriers to evidence-based nursing practice utilization. The purpose of the study was to assess the barriers to evidence-based nursing practice utilization from the perspective of nurse managers. A descriptive comparative design was used. The study was conducted at Menoufia University hospital and Shebin El-Kom Teaching hospital. A convenient sample was used to select 90 nurse managers. Data was collected using the perceived barriers questionnaire. Nurse managers reported that there barriers related to perceived value of research (e,g, lack of interest, 74.4\%), personal (inadequate computer skills, 50.0\%) and administrative (lack of knowledge about research, 66.70\%). So, it was concluded that nurse managers were challenged by a large number of barriers It was recommended that the results of the study should be disseminated among the important key persons (nurse managers).
\end{abstract}

Key words: Evidence based nursing practice (EBNP), Barriers, Nurse Managers.

\section{Introduction}

In recent decades; the nursing discipline has begun to pay much greater attention to the necessity of the use of research findings into practice (Ezz, Zahran and El-Soussi , 2013). Evidence based utilization in nursing is the most important piece of the research process. Without such utilization, the research process is simply an exercise in academics. Evidence based utilization is now a part of the nurses' professional role and responsibility, which has been intertwined with concepts of efficiency, effectiveness, and quality improvement. In a profession such nursing, it is important that nurses demonstrate their practices as effective, efficient and more likely to be appropriate and justifiable (Squires, 2017).

Evidence based practice has been recognized by health care institutions as the gold standard for provision of safe and effective health care(Cruz etal.,2016).Society increasingly demands that health care be based on the best available evidence. Nurses have a societal obligation to use practices that are based on sound scientific evidence. The time from scientific discovery or publication of research to implementation in practice is lengthy and needs to be shortened. Nurse Managers can speed this process by using scientifically based strategies to facilitate the translation of research into practice (Wise, 2014).

Evidence-based practice (EBP) is a process designed to support and inform clinical and administrative decisionmaking by combining (a) the best available scientific evidence with regulatory and accreditation requirements for practice, (b) individual clinical, staff, leadership, and management judgment and expertise, and (c) patient and staff preferences (Stevens, 2013).

EBP is crucial in the overall health care delivery system because it can help reduce escalating health care costs, save time, afford better patient outcomes, and provide nurses with more autonomy in their practice, which can ultimately lead 
to greater job satisfaction and increased nurses' retention (Melnyk and Fineout Overholt , 2015).

Despite the significant amount of literature regarding the benefits of EBP and nurses' positive attitudes toward it, there are many barriers for implementing EBP, and the process of implementing EBP is slow. Common barriers include: Lack of time to search for evidence, lack of understanding and interpreting skills for research findings, inadequate access to information technology, limited information technology (IT) skills, lack of autonomy to change practice, and lack of information searching skills (AlMomani, Al-Barmawi , Al-Hadid, and Aljabery , 2016). Many factors however, can facilitate use of EBP implementation including adequate time, education, access to information, organizational support, mentors, resources, increased awareness of and a positive attitude towards EBP (Davidson and Brown, 2014).

Additionally, the implementation of EB best practices is not just an individual, staff nurse- level pursuit. Too few nurses understand what best practices and evidence based practice are all about, and many organizational cultures do not support nurses who seek out and use research to change long standing practices, rooted in tradition rather than in science. Administrative support is needed to facilitate the utilization of evidence based nursing into practice (Prevost and Salyer, 2010).

Nurse Managers are administrative leaders accountable for the quality of patient care, exerting both expert knowledge and administrative power in the clinical setting, and are the connection between staff nurses and those on the executive level. Nurse Managers could be both a facilitator and a barrier to EBP. They could provide resources, encourage nurses and connect various stakeholders for evidence- based initiatives. Conversely, they can be considered a major barrier if nurses perceive they do not have adequate support from managers(Cheng, Feng, $\mathrm{Hu}$ and Broome , 2018). In view of these two contrasting perspectives of their role in influencing evidence implementation in nursing practice, active engagement of nurse managers is needed for practice change to occur (Davidson and Brown, 2014).

Significance of the study:

Worldwide, nurse managers (NMs) play an important role in promoting evidence-based practice (EBP) despite the extensive amount of research that has been conducted to evaluate evidence-based practice implementation; these practices have not been sufficiently incorporated into nursing practice in Egypt. Therefore, this study was done to Assess the barriers to evidence-based nursing practice utilization from the perspectiveness of nurse managers.

\section{Purpose of the study:}

This study was conducted to assess the barriers to evidence-based nursing practice utilization from the perspectiveness of nurse managers.

\section{Research questions:}

-What are the perceived barriers that affect nurse managers' abilities to utilize evidence based nursing practice?

\section{Methods}

Research design: A descriptive comparative design was used in conducting this study.

Sample: A convenient sample of 90 nurse managers was recruited from Menoufia University hospital and Shebin El-kom Teaching hospital.

Inclusion criteria: They should have at least two years of experience working in the hospital. 


\section{Barriers to Evidence-Based Nursing Practice Utilization from the Perspective of Nurse Managers}

Setting: This study was conducted in Menoufia University Hospital and Shebin El-kom Yeaching hospital.

Data collection instruments: A structured questionnaire was used for data collection.

Perceived barriers questionnaire: This instrument was adopted from Funk et al., (1991) and modified by the investigator based on the literature review. It contained two parts:

- Part one displayed the sociodemographic characteristics of nurses such as name of hospital, age, nursing position, nursing qualifications, years of clinical experience, work place.

- Part two contained the barriers of evidence based practices. It consisted of 40 items. divided into five groups of barriers with 3-point response likert scales where "3" indicated "Agree"; score " 2 " for "Neutral"; and score "1" for "Disagree". There were five groups of "Barriers" such as perceived value of research, information resources, personal barriers, administrative and barriers of perceived utilization.

\section{Validity:}

A bilingual group of five experts was selected to test the content and face validity of the instruments. The panel included two professors from nursing administration department, two professors from Medical Surgical Nursing departments and one professor from Community Health Nursing department (Faculty of Nursing, Menoufia University). Necessary modifications and deleting of some questions were done to reach the final valid version of the instruments. The instruments were considered valid from the experts' perspective.

Reliability:

\section{Perceived barriers questionnaire:.}

The instrument was tested to reliability by the internal consistency coefficient alpha $(\mathrm{a}=0.92)$.

\section{Methods:}

Before any attempt to collect data, an official letter was submitted to the Dean of the Nursing College to collect data from the pre-mentioned study settings. Also, written letters were submitted to the director of Teaching Hospital and the director of University Hospital to collect data from the pre-mentioned study subjects. The letter contained the title, purpose of the study, and methods of data collection.

\section{Ethical consideration:}

The study was conducted with careful attention to ethical standards of research and rights of the participants:-

\section{- Informed consent:}

The respondents were informed that participation was voluntary participation. So that informed consent was obtained by explaining the purpose, nature, time of conducting the study, potential benefits of the study and how data will be collected.

- Anonymity and Confidentiality:

The respondents were assured that the data will be treated as strictly confidential as possible. They were reassured that they weren't required to mention their names.

\section{Pilot study}

The pilot study was carried on 9 nurse managers. They represented $10 \%$ of sample size. The purpose of the pilot study was to ascertain clarity, relevancy, applicability of the study instruments and to determine obstacles that may be encountered during data collection. It also helped to estimate the time needed to fill the questionnaires. Based on the results of the pilot, no modifications were done to the instruments. The 
piloted sample were included in the final sample.

\section{Statistical design:}

The collected data were categorized, tabulated, analyzed and presented in descriptive forms by using SPSS version 18.The necessary tables were then prepared and statistical analysis included the arithmetic mean, standard deviation, chi-square test, $\mathrm{t}$ test and Pearson correlation (r).

\section{Results}

Table 1 represents socio- demographic characteristics of the studied subjects in the studied settings. As shown in the table, the highest percentage of the studied subjects were from University Hospital and were between 35-<45 years old. Also, the highest percentage of the studied subjects had Bachelor degree in nursing and most of them were head nurses. Regarding years of experience, the highest percentage of the studied subjects had more than or equal 15 years of experience and worked in critical care units.

Table 2 illustrates total mean percentage of barriers of EBNP as reported by the studied subjects. As noticed from the table, percentage of barriers of EBNP constitutes 84.5\%. Additionally, it showed that administrative barriers constitute the highest mean's percentage while personal barriers constitute the lowest mean's percentage.

Table 3 illustrates mean score of the studied subjects regarding barriers of the perceived value of research and EBNP. It revealed that the highest mean score of the studied subjects was the 5th item (Insufficient time on the job to read research), while the lowest mean score of the studied subjects was the 2nd item (Nurses do not see the value of research for practice).

Table 4 Illustrates mean score of the studied subjects regarding barriers of information resources. It revealed that the highest mean score of the studied subjects was the 1 st item (Lack of awareness of nurses about research or EBP), while the lowest mean score of the studied subjects was the 7 th item (The amount of research information is overwhelming).

Table 5 illustrates mean's score of the studied subjects regarding personal barriers of EBNP. It revealed that the highest mean score of the studied subjects was the 8th item (Nurses do not have time to read research), while the lowest mean score of the studied subjects was the 1st item (Inadequate computer skills).

Table 6 illustrates mean's score of the studied subjects regarding barriers of perceived use of EBNP. It revealed that the highest mean score of the studied subjects was the 7th item (Inability to implement recommendations of research studies into clinical practice), while the lowest mean score of the studied subjects was the 3rd item (The research is not relevant to the nurse's practice.).

Table 7 illustrates mean's score of the studied subjects regarding administrative barriers of evidence based practice. It revealed that the highest mean score of the studied subjects was the 2nd item (Administration perceived EBP as a low management priority), and the 3rd item (There is no support or incentives for clinical practice development) respectively, while the lowest mean score of the studied subjects was the 5th item (Lack of education about the research process).

$\underline{\text { Fig } 1}$ Presents ranking percent of the 1st ten barriers for EBNP utilization as reported by the studied subjects. It reflected that the highest ranked barrier for EBNP utilization by the studied subjects (93.33\%) was lack of awareness of nurses about research or EBP. 
Table (1): Socio- Demographic Characteristics of the Studied Subjects in the Studied Settings $(\mathrm{N}=90)$.

\begin{tabular}{|c|c|c|c|}
\hline \multicolumn{2}{|c|}{ Socio-demographic characteristics Items } & No & $\%$ \\
\hline \multirow{2}{*}{ Hospital name } & University Hospital & 56 & $62.22 \%$ \\
\hline & Teaching Hospital & 34 & $37.78 \%$ \\
\hline \multirow{3}{*}{ Age } & $25-<35$ years & 10 & $11.11 \%$ \\
\hline & $35-<45$ years & 63 & $70.00 \%$ \\
\hline & $\geq 45$ years & 17 & $18.89 \%$ \\
\hline \multirow{4}{*}{ Educational Qualification } & Bachelor degree in nursing & 58 & $64.44 \%$ \\
\hline & Professional diploma in nursing & 19 & $21.11 \%$ \\
\hline & Master degree in nursing & 12 & $13.33 \%$ \\
\hline & Doctorate degree in nursing & 1 & $1.11 \%$ \\
\hline \multirow{4}{*}{ Job title } & Nursing director & 2 & $2.22 \%$ \\
\hline & Vice director & 7 & $7.78 \%$ \\
\hline & Nursing supervisor & 18 & $20.00 \%$ \\
\hline & Head nurse & 63 & $70.00 \%$ \\
\hline \multirow{3}{*}{ Years of Experience } & $5-<10$ years & 3 & $3.33 \%$ \\
\hline & $10-<15$ years & 32 & $35.56 \%$ \\
\hline & $\geq 15$ years & 55 & $61.11 \%$ \\
\hline \multirow{4}{*}{ Department } & Inpatient departments & 29 & $32.22 \%$ \\
\hline & Critical care units & 40 & $44.44 \%$ \\
\hline & Nursing administration department & 9 & $10.00 \%$ \\
\hline & $\begin{array}{l}\text { Specialized units (Infection control unit, } \\
\text { quality assurance unit and continuing } \\
\text { education unit). }\end{array}$ & 12 & $13.33 \%$ \\
\hline
\end{tabular}

Table (2): Mean of Nurse Managers Reported Perception of Barriers for EBNP

\begin{tabular}{|c|c|c|c|c|}
\hline Categories of Barriers of EBNP & Mean & SD & $\begin{array}{c}\text { Mean's } \\
\text { percentage }\end{array}$ & Rank \\
\hline Total barriers of EBNP & 101.4 & 11.86 & $84.5 \%$ & \\
\hline $\begin{array}{l}\text { Total barriers of the perceived value of research and } \\
\text { EBNP }\end{array}$ & 15.76 & 1.7 & $87.56 \%$ & 3 \\
\hline Total barriers of information resources & 31.6 & 3.89 & $87.78 \%$ & 2 \\
\hline Total personal barriers of EBNP & 18.73 & 4.07 & $78.04 \%$ & 5 \\
\hline Total barriers of perceived use of EBNP & 22.01 & 3.66 & $81.52 \%$ & 4 \\
\hline Total administrative barriers of EBNP & 13.3 & 2.1 & $88.67 \%$ & 1 \\
\hline
\end{tabular}

Table (3): Mean of Nurse Managers Reported Perception of Barriers for Value of Research in Relation to EBNP

\begin{tabular}{|c|c|c|c|c|c|c|c|c|}
\hline & \multicolumn{2}{|c|}{$\begin{array}{l}\text { Barriers of the perceived value of } \\
\text { research and EBNP }\end{array}$} & Disagree & Neutral & Agree & Mean & SD & $\begin{array}{c}\text { Mean's } \\
\text { percentage }\end{array}$ \\
\hline \multirow[t]{2}{*}{1} & \multirow{2}{*}{$\begin{array}{l}\text { Lack of interest to research } \\
\text { process }\end{array}$} & No & 4 & 19 & 67 & \multirow[t]{2}{*}{2.7} & \multirow[t]{2}{*}{0.55} & \multirow[t]{2}{*}{$90.00 \%$} \\
\hline & & $\%$ & $4.40 \%$ & $21.10 \%$ & $74.40 \%$ & & & \\
\hline \multirow[t]{2}{*}{2} & \multirow{2}{*}{$\begin{array}{l}\text { Nurses do not see the value of } \\
\text { research for practice }\end{array}$} & No & 4 & 36 & 50 & \multirow[t]{2}{*}{2.5} & \multirow[t]{2}{*}{0.58} & \multirow[t]{2}{*}{$83.70 \%$} \\
\hline & & $\%$ & $4.40 \%$ & $40.00 \%$ & $55.60 \%$ & & & \\
\hline
\end{tabular}




\section{Barriers to Evidence-Based Nursing Practice Utilization from the Perspective of Nurse Managers}

\begin{tabular}{|c|c|c|c|c|c|c|c|c|}
\hline \multirow[t]{2}{*}{3} & \multirow{2}{*}{$\begin{array}{l}\text { Nurses do not feel enough } \\
\text { authority to change patient care } \\
\text { practices/ lack of authority to } \\
\text { change patient care practices }\end{array}$} & No & 3 & 33 & 54 & \multirow[t]{2}{*}{2.6} & \multirow[t]{2}{*}{0.56} & \multirow[t]{2}{*}{$85.56 \%$} \\
\hline & & $\%$ & $3.30 \%$ & $36.70 \%$ & $60.00 \%$ & & & \\
\hline \multirow[t]{2}{*}{4} & \multirow{2}{*}{$\begin{array}{l}\text { Nurses feel the benefits of } \\
\text { changing practice will be } \\
\text { minimal. }\end{array}$} & No & 6 & 29 & 55 & \multirow[t]{2}{*}{2.5} & \multirow[t]{2}{*}{0.62} & \multirow[t]{2}{*}{$84.81 \%$} \\
\hline & & $\%$ & $6.70 \%$ & $32.20 \%$ & $61.10 \%$ & & & \\
\hline \multirow[t]{2}{*}{5} & \multirow{2}{*}{$\begin{array}{l}\text { Insufficient time on the job to } \\
\text { read research }\end{array}$} & No & 2 & 17 & 71 & \multirow[t]{2}{*}{2.8} & \multirow[t]{2}{*}{0.47} & \multirow[t]{2}{*}{$92.22 \%$} \\
\hline & & $\%$ & $2.20 \%$ & $18.90 \%$ & $78.90 \%$ & & & \\
\hline \multirow[t]{2}{*}{6} & \multirow[b]{2}{*}{$\begin{array}{l}\text { Lack of compliance of relevant } \\
\text { literature in one place }\end{array}$} & No & & 30 & 60 & \multirow[t]{2}{*}{2.7} & \multirow[t]{2}{*}{0.47} & \multirow[t]{2}{*}{$88.89 \%$} \\
\hline & & $\%$ & & $33.30 \%$ & $66.70 \%$ & & & \\
\hline
\end{tabular}

Table (4): Mean's Score of Nurse Managers Reported Perception of Barriers for Information Resources in Relation to EBNP

\begin{tabular}{|c|c|c|c|c|c|c|c|c|}
\hline & \multicolumn{2}{|l|}{ Barriers of information resources } & Disagree & Neutral & Agree & mean & SD & Mean's \\
\hline \multirow[t]{2}{*}{1} & \multirow{2}{*}{$\begin{array}{l}\text { Lack of awareness of nurses about } \\
\text { research or EBP. }\end{array}$} & No & 3 & 12 & 75 & \multirow[t]{2}{*}{2.8} & \multirow[t]{2}{*}{0.48} & \multirow[t]{2}{*}{$93.33 \%$} \\
\hline & & $\%$ & $3.30 \%$ & $13.30 \%$ & $83.30 \%$ & & & \\
\hline \multirow[t]{2}{*}{2} & \multirow{2}{*}{$\begin{array}{l}\text { Research reports are published in a foreign } \\
\text { language. }\end{array}$} & No & 9 & 20 & 61 & \multirow[t]{2}{*}{2.58} & \multirow[t]{2}{*}{0.67} & \multirow[t]{2}{*}{$85.93 \%$} \\
\hline & & $\%$ & $10.00 \%$ & $22.20 \%$ & $67.80 \%$ & & & \\
\hline \multirow[t]{2}{*}{3} & \multirow{2}{*}{$\begin{array}{l}\text { Research reports/ articles are not published } \\
\text { fast enough }\end{array}$} & No & 5 & 25 & 60 & \multirow[t]{2}{*}{2.61} & \multirow[t]{2}{*}{0.59} & \multirow[t]{2}{*}{$87.04 \%$} \\
\hline & & $\%$ & $5.60 \%$ & $27.80 \%$ & $66.70 \%$ & & & \\
\hline \multirow[t]{2}{*}{4} & \multirow{2}{*}{$\begin{array}{l}\text { Research reports/ articles are not readily } \\
\text { available }\end{array}$} & No & & 23 & 67 & \multirow[t]{2}{*}{2.74} & \multirow[t]{2}{*}{0.49} & \multirow[t]{2}{*}{$91.48 \%$} \\
\hline & & $\%$ & & $25.60 \%$ & $74.40 \%$ & & & \\
\hline \multirow[t]{2}{*}{5} & \multirow{2}{*}{$\begin{array}{l}\text { Access to research evidence is poor (slow } \\
\text { or no computers or data bases). }\end{array}$} & No & & 30 & 60 & \multirow[t]{2}{*}{2.67} & \multirow[t]{2}{*}{0.47} & \multirow[t]{2}{*}{$88.89 \%$} \\
\hline & & $\%$ & & $33.30 \%$ & $66.70 \%$ & & & \\
\hline \multirow[t]{2}{*}{7} & & No & 13 & 29 & 48 & 2.39 & 0.73 & $79.63 \%$ \\
\hline & overwhelming. & $\%$ & $14.40 \%$ & $32.20 \%$ & $53.30 \%$ & & & \\
\hline 8 & Inadeguate understandino of research & No & 11 & 27 & 52 & 2.46 & 0.70 & $81.85 \%$ \\
\hline & terms used in research articles. & $\%$ & $12.20 \%$ & $30.00 \%$ & $57.80 \%$ & & & \\
\hline 9 & The hosnital has no dissemination research & No & 2 & 20 & 68 & 2.73 & 0.49 & $91.11 \%$ \\
\hline & center. & $\%$ & $2.20 \%$ & $22.20 \%$ & $75.60 \%$ & & & \\
\hline 10 & Superiors do not communicate the new & No & 5 & 24 & 61 & 2.62 & 0.59 & $87.41 \%$ \\
\hline & evidences with subordinates (staff). & $\%$ & $5.60 \%$ & $26.70 \%$ & $67.80 \%$ & & & \\
\hline 11 & Nurses are isolated from knowledgeable & No & 3 & 25 & 62 & 2.66 & 0.54 & $88.52 \%$ \\
\hline
\end{tabular}

Table (5): Mean's Score of the Studied Subjects Regarding Personal Barriers of $\operatorname{EBNP}(\mathrm{N}=90)$. 
Barriers to Evidence-Based Nursing Practice Utilization from the Perspective of Nurse Managers

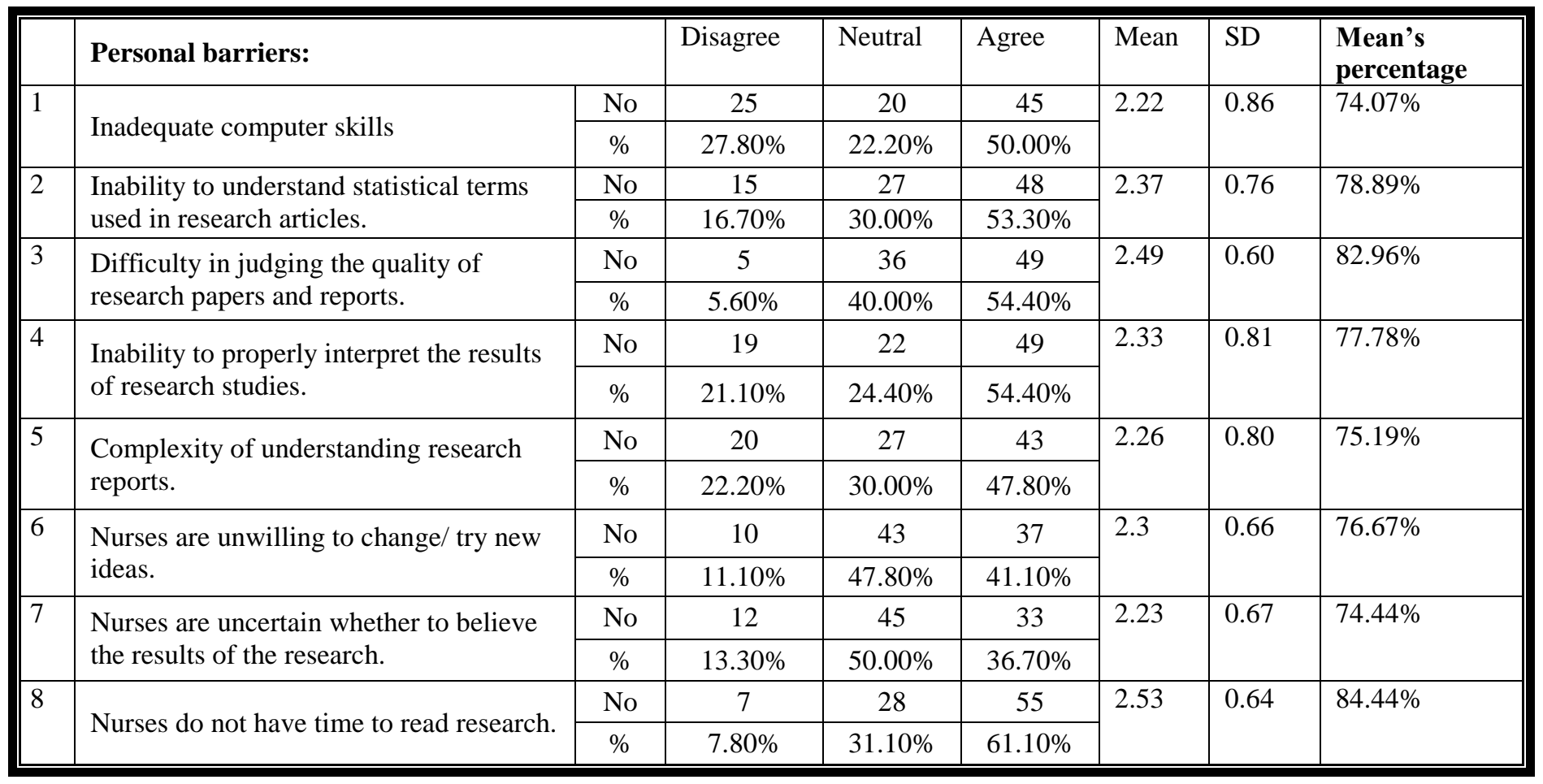

Table (6): Mean's Score of the Studied Subjects Regarding Barriers of Perceived Use of $\operatorname{EBNP}(\mathrm{N}=90)$.

\begin{tabular}{|c|c|c|c|c|c|c|c|c|}
\hline & \multicolumn{2}{|l|}{ Barriers use } & Disagree & Neutral & Agree & Mean & SD & Mean's \\
\hline \multirow[t]{2}{*}{1} & \multirow{2}{*}{$\begin{array}{l}\text { Unavailability of research reports/ } \\
\text { articles. }\end{array}$} & No & 12 & 25 & 53 & \multirow[t]{2}{*}{2.46} & \multirow[t]{2}{*}{0.72} & \multirow[t]{2}{*}{$81.85 \%$} \\
\hline & & $\%$ & $13.30 \%$ & $27.80 \%$ & $58.90 \%$ & & & \\
\hline \multirow[t]{2}{*}{2} & \multirow{2}{*}{$\begin{array}{l}\text { The research is not reported clearly } \\
\text { and readably. }\end{array}$} & No & 2 & 38 & 50 & \multirow[t]{2}{*}{2.53} & \multirow[t]{2}{*}{0.54} & \multirow[t]{2}{*}{$84.44 \%$} \\
\hline & & $\%$ & $2.20 \%$ & $42.20 \%$ & $55.60 \%$ & & & \\
\hline \multirow[t]{2}{*}{3} & \multirow{2}{*}{$\begin{array}{l}\text { The research is not relevant to the } \\
\text { nurse's practice. }\end{array}$} & No & 23 & 36 & 31 & \multirow[t]{2}{*}{2.09} & \multirow[t]{2}{*}{0.77} & \multirow[t]{2}{*}{$69.63 \%$} \\
\hline & & $\%$ & $25.60 \%$ & $40.00 \%$ & $34.40 \%$ & & & \\
\hline \multirow[t]{2}{*}{4} & \multirow{2}{*}{$\begin{array}{l}\text { Conflicting results of the literature } \\
\text { reports (research results of the same } \\
\text { subject sometimes are different). }\end{array}$} & No & 17 & 35 & 38 & \multirow[t]{2}{*}{2.23} & \multirow[t]{2}{*}{0.75} & \multirow[t]{2}{*}{$74.44 \%$} \\
\hline & & $\%$ & $18.90 \%$ & $38.90 \%$ & $42.20 \%$ & & & \\
\hline \multirow[t]{2}{*}{5} & \multirow{2}{*}{$\begin{array}{l}\text { Insufficient research resources to } \\
\text { implement EBP. }\end{array}$} & No & 4 & 30 & 56 & \multirow[t]{2}{*}{2.58} & \multirow[t]{2}{*}{0.58} & \multirow[t]{2}{*}{$85.93 \%$} \\
\hline & & $\%$ & $4.40 \%$ & $33.30 \%$ & $62.20 \%$ & & & \\
\hline \multirow[t]{2}{*}{6} & \multirow{2}{*}{$\begin{array}{l}\text { Insufficient time at workplace to } \\
\text { implement changes in their current } \\
\text { practice. }\end{array}$} & No & 1 & 35 & 54 & \multirow[t]{2}{*}{2.59} & \multirow[t]{2}{*}{0.52} & \multirow[t]{2}{*}{$86.30 \%$} \\
\hline & & $\%$ & $1.10 \%$ & $38.90 \%$ & $60.00 \%$ & & & \\
\hline \multirow[t]{2}{*}{7} & \multirow{2}{*}{$\begin{array}{l}\text { Inability to implement } \\
\text { recommendations of research } \\
\text { studies into clinical practice. }\end{array}$} & No & & 31 & 59 & \multirow[t]{2}{*}{2.66} & \multirow[t]{2}{*}{0.48} & $88.52 \%$ \\
\hline & & $\%$ & & $34.40 \%$ & $65.60 \%$ & & & \\
\hline 8 & Implications for practice are not & No & 2 & 37 & 51 & 2.54 & 0.54 & $84.81 \%$ \\
\hline & made clear. & $\%$ & $2.20 \%$ & $41.10 \%$ & $56.70 \%$ & & & \\
\hline 9 & The conclusions drawn from the & No & 10 & 40 & 40 & 2.33 & 0.67 & $77.78 \%$ \\
\hline & research are not justified. & $\%$ & $11.10 \%$ & $44.40 \%$ & $44.40 \%$ & & & \\
\hline
\end{tabular}




\section{Barriers to Evidence-Based Nursing Practice Utilization from the Perspective of Nurse Managers}

Table (7): Mean Score of Nurse Managers Reported Perception of Administrative Barriers for EBNP $(\mathrm{N}=90)$.

\begin{tabular}{|c|c|c|c|c|c|c|c|c|}
\hline & \multicolumn{2}{|l|}{ Administrative Barriers } & Disagree & Neutral & Agree & Mean & SD & Mean's \\
\hline \multirow[t]{2}{*}{1} & \multirow{2}{*}{$\begin{array}{l}\text { There is not a documented need to change } \\
\text { practice. }\end{array}$} & No & 6 & 17 & 67 & \multirow[t]{2}{*}{2.68} & \multirow[t]{2}{*}{0.59} & \multirow[t]{2}{*}{$89.26 \%$} \\
\hline & & $\%$ & $6.70 \%$ & $18.90 \%$ & $74.40 \%$ & & & \\
\hline \multirow[t]{2}{*}{2} & \multirow{2}{*}{$\begin{array}{l}\text { Administration perceived EBP as a low } \\
\text { management priority. }\end{array}$} & No & 2 & 24 & 64 & \multirow[t]{2}{*}{2.69} & \multirow[t]{2}{*}{0.51} & \multirow[t]{2}{*}{$89.63 \%$} \\
\hline & & $\%$ & $2.20 \%$ & $26.70 \%$ & $71.10 \%$ & & & \\
\hline \multirow[t]{2}{*}{3} & \multirow{2}{*}{$\begin{array}{l}\text { There is no support or incentives for } \\
\text { clinical practice development. }\end{array}$} & No & 4 & 20 & 66 & \multirow[t]{2}{*}{2.69} & \multirow[t]{2}{*}{0.55} & \multirow[t]{2}{*}{$89.63 \%$} \\
\hline & & $\%$ & $4.40 \%$ & $22.20 \%$ & $73.30 \%$ & & & \\
\hline \multirow[t]{2}{*}{4} & \multirow{2}{*}{$\begin{array}{l}\text { There is resistance to make changes in the } \\
\text { work setting }\end{array}$} & No & 6 & 20 & 64 & \multirow[t]{2}{*}{2.64} & \multirow[t]{2}{*}{0.60} & \multirow[t]{2}{*}{$88.15 \%$} \\
\hline & & $\%$ & $6.70 \%$ & $22.20 \%$ & $71.10 \%$ & & & \\
\hline \multirow[t]{2}{*}{5} & \multirow{2}{*}{$\begin{array}{l}\text { Lack of education about the research } \\
\text { process. }\end{array}$} & No & 6 & 24 & 60 & \multirow[t]{2}{*}{2.6} & \multirow[t]{2}{*}{0.61} & \multirow[t]{2}{*}{$86.67 \%$} \\
\hline & & $\%$ & $6.70 \%$ & $26.70 \%$ & $66.70 \%$ & & & \\
\hline
\end{tabular}
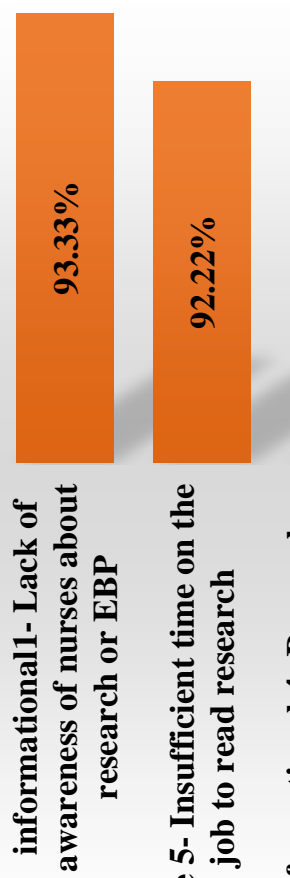
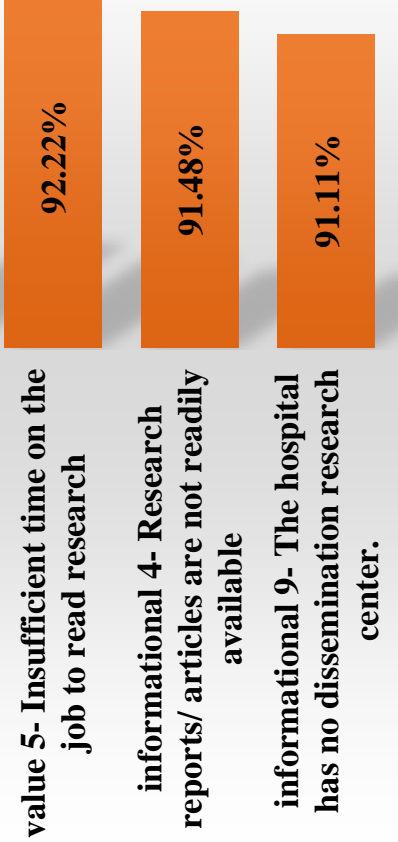
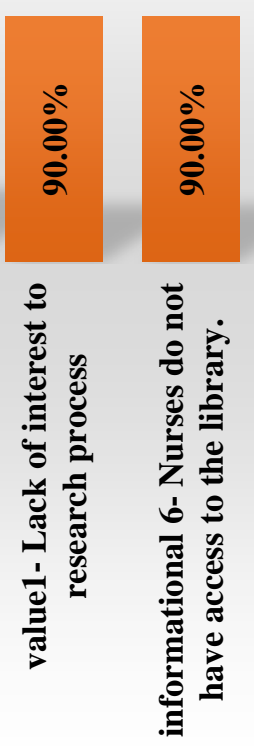
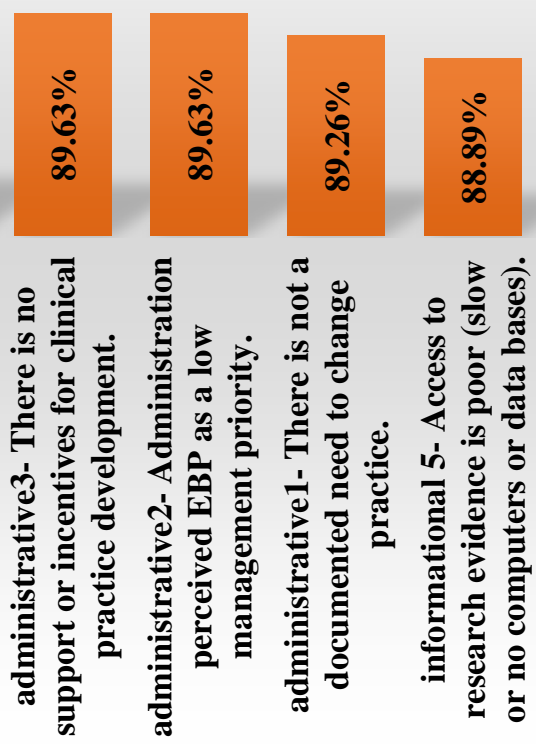

Figure (1): Ranking Percent of the $1^{\text {st }}$ Ten Barriers for EBNP Utilization as Reported by the

\section{Discussion}

Concerning the answer of the research question ("What are the perceived barriers that influence nurse managers' abilities for evidence based nursing practice utilization?"). The findings of the present study showed that the major barriers to EBNP use were administrative barriers. This finding agrees with Shazly, Abdel- Azeem, and Ahmed (2018), and Shifaza etal., (2014) who reported that organizational factors were the highest barriers regarding EBP. 
Also, personal barriers were the lowest barriers impeding the current study subjects to use EBP. This was congruent with Ali (2014).

From the investigators' point of view, these findings may be because both hospitals in the current study have limited financial and human resources. First, the limitation of the financial resources leads to a difficulty in applying the study findings which may need extra-equipment and materials, an absence of incentives for the application of researches, and an absence of financial support to fund accessing fulltext nursing articles or even a library containing up-to-date textbooks. Second, the shortage of the staff members may limit nursing staff time to read and apply research findings and hinder the administrative authorities and other heath team members to support nurses to utilize research.

Concerning organizational barriers:

In the present study, nurse managers reported that administration perceived EBP as a low management priority and there is no support or incentives for clinical practice development. These were the top administrative barriers, while the lowest perceived administrative barrier was for lack of education about the research and EBP process.

From the investigators' point of view, this result could be related to the nurse managers feel a lack of support, encouragement and cooperation from their hospitals. Also, there is limited organizational budget which impede EBP incorporation. This may lead to the higher level of perceived barriers related to "organization" as one of the main research utilization determinants.

This was supported by Chien, Bai and Wong (2013) who argued that importance of research utilization in nursing practice was not supported by central government agency or Ministry of Health, which could better equip nurses with research knowledge and skills and increase their responsibility and opportunities for being involved in research utilization. Also, they lacked facilities required to review or conduct research and they have only scarcity of research findings could be generalized to their settings.

Furthermore, a study done by Pryse (2012) was revealed that a lack of administrative support, a work environment not receptive to changing practice, and lack of management support, lack of financial support were frequently identified barriers and can be directly attributed to the work environment's impedes on the nurse's ability to engage in EBP.

Concerning personal barriers and barriers of the perceived value of research and EBNP. The present study revealed that highest mean score of the studied nurse managers was that they did not have time to read research. From the investigators' point of view, this could be attributed to that both hospitals were not interested in to incorporate the EBP culture. also, heavy workload as both hospitals are the largest hospitals at Menofia Governorate and offered healthcare services to a great number of patients which make load on nursing management' priorities. This was supported by Varaei et al., (2013) who reported that in the human resource category, shortage of nurses and heavy workload are the most common barriers to implementation of EBP.

This was supported by Dalheim , Harthug, Nilsen and Nortvedt (2012) who stated that lack of time is regarded as a hindrance to the implementation of EBP. Healthcare institutions tend to have a culture of 'busyness' which is valued and rewarded and which does not encourage nurses to spend time sitting and reading, but instead rewards those who visibly engage in duties with their patients .Lack of time is also linked to increased workload. 


\section{Barriers to Evidence-Based Nursing Practice Utilization from the Perspective of Nurse Managers}

Similar to these results, Williams, Perillo and Brown (2015) found high workload to be a major barrier to the implementation of EBP, primarily because it undermines the amount of time available for nurses to read EBPrelated research. In addition, the result of previous study Stokke, Olsen, Espehaug and Nortvedt (2014) revealed that lacking time and busier working were the greatest barrier.

This was consistent with Mahmoud (2013) who stated that lack of time reflects the serious and deep seated problem that exists in Egypt as well as other hospitals all over the world. Time to read, evaluate, analyze, disseminate and implement research is very limited for nurses everywhere.

Concerning barriers of information resources, the present study revealed that the highest mean score of the studied subjects was the lack of awareness of nurses about research or EBP. From the investigators' point of view, this result could be related to inadequate knowledge and skills in EBP and both hospitals had no research center. Also, access to research evidence was difficult.

In the same line, Chiu, et al., (2010) found that there are many barriers to the utilization of EBP which include nurses' unaware of evidence that could be used to improve patient outcomes. This was consistent with Maaskant et al., (2013) who showed that nurses had little understanding and did not know research utilization terms which could be a serious barrier for nurses.

Furthermore, the present study was congruent with a study conducted by $\mathrm{Ez}$ elarab et al., (2012) which emphasized that many nurses in clinical practice were unfamiliar with evidence based nursing concepts and infrequently used sources of new information and new research evidence in their practice and don't know how to incorporate this approach into general clinical practice settings.

On the other side of the coin, Bahadori, Raadabadi, Ravangard and Mahaki, (2016) found that the lack of awareness of research was the least important barrier to the application of research findings from the studied nurses' perspective.

Concerning barriers of perceived use of EBNP:The present study revealed that the highest barrier was the inability to implement recommendations of research studies into clinical practice. This might have more than one explanation; the first was that evidence based practice was not applied in the hospital. The second wthat both hospitals had no research centers The third was that both hospitals in the current study have limited financial and human resources which lead to a difficulty in applying the study findings. Hassan, (2016) showed that nurses had difficulty in determining applicability of research findings and inability to implement recommendations of research studies into clinical practice. Concerning the top ten barriers of EBNP, they were lack of awareness of nurses about research or EBP, insufficient time on the job to read research, research reports/ articles are not readily available, the hospital has no dissemination research center, lack of interest to research process, nurses do not have access to the library, there is no support or incentives for clinical practice development, administration perceived EBP as a low management priority, there is not a documented need to change practice, and access to research evidence is poor (slow or no computers or data bases).

In contrast Ezz, Zahran and El-Soussi (2013) found that the top ten barriers identified were insufficient time to read research during the on-duty and offduty hours, poor access to research evidence, insufficient time to implement new ideas, inadequate 
facilities, unavailable research reports/articles in work setting, lack of authority to change patient care, lack of awareness regarding the research process, nonexistence of research disseminating center, and resistance to change as a normal response in any change process.

The differences between the results of the present study and those of other studies mentioned above can be due to the differences between the settings and culture of the organization in which the study was conducted. This is supported by Ezz, Zahran and El-Soussi (2013) who mentioned that the differences in ranking of barriers may be attributed to the differences in the settings and individual characteristics of nurses or might be educational background of studied participants. In the same line Bahadori et al., (2016) mentioned that the differences in ranking of barriers can be due to the differences between the environmental conditions of each organization and strategies used to provide nursing care for patients.

\section{Recommendations}

Based on the findings of this study and the review of the literature, the following recommendations are proposed:

\section{At practical level:}

- Tthe study results should be disseminated to the important key persons (nurse managers) to be considered.

\section{At administration level:}

- Barriers to evidence based nursing practice implementation should be studied.

- Hospital administrators should give nurses sufficient time to learn skills of evidence based practice

- Access to libraries, computers and internet for online search of EB nursing practice should be facilitated.

- Online resources and electronic databases should be available for all the nurses at least in each unit or department to allow them to document, search and get their patients' related information and the appropriate nursing care.

- Small libraries (research corner) containing recent research articles and references should be established in each unit, department, or floor to overcome the barrier of nurses' time shortage and allow them to review research findings easily.

- A reward system should be established for nurses interested in EBP may be needed to help profile innovative practice.

At research level:

- Replication of the study on large sample size and different settings.

\section{Reference}

Ali, K. A. G., (2014). Enhancing Bachelor nurses to use evidencebased nursing in clinical practice. Unpublished Doctorate thesis (Ph.D.) in Nursing Service Administration. Faculty of Nursing Benha University. P.140.

Al-Momani, M, Al-Barmawi, M, AlHadid, L, and Aljabery ,A.(2016). Developing a tool that explores factors influencing the adoption of evidence-based principles in nursing practice in Jordan. Applied Nursing Research 32 (2016) 122-127.

Bahadori, Raadabadi, Ravangard and Mahaki (2016). The barriers to the application of the research findings from the nurses' perspective: A case study in a teaching hospital. Journal of Education and Health Promotion | Vol. 5 | June 2016

Cheng, L, Feng ,S, Hu, Y, Broome, M.(2018). Leadership practices of nurse managers for implementing evidence-based nursing in China. J Nurs Manag. 2018 Sep;26(6):671-678. doi: 10.1111/ jonm. 12594. Epub 2018 Feb 21. 


\section{Barriers to Evidence-Based Nursing Practice Utilization from the Perspective of Nurse Managers}

Chien, W, Bai, Q, Wong, W, Wang, H and Lu, X. (2013) Nurses' perceived barriers to and facilitators of research utilization in mainland China: a crosssectional survey. The open nursing journal 7(1). 96- 106. DOI: $\quad 10.2174 / 1874434 \quad 6013$ 07010096

Chiu, Y, Weng, Y, Lo, H, Hsu, C, Shih, Yand Kuo, K. (2010). Comparison of evidence-based practice between physicians and nurses: A national survey of regional hospitals in Taiwan. Journal of Continuing Education in the Health Professions, 30(2), 132138

Cruz, J. P., Colet, P. C., Alquwez, N., Alqubeilat, H., Bashtawi, M. A., Ahmed, E. A., \& Cruz, C. P. (2016). EvidenceBased Practice Beliefs and Implementation among the Nursing Bridge Program Students of a Saudi University. International Journal of Health Sciences, 10(3), 405414.

Dalheim, A, Harthug, S, Nilsen, R and Nortvedt, M (2012). Factors influencing the development of evidence-based practice among nurses: A self-report survey. BMC Health Serv Res 2012;2012(12):367.

http://dx.doi.org/10.1186/14726963-12-367

Davidson ,J and Brown, C.(2014). Evaluation of nurse engagement in evidence-based practice. AACN Adv Crit Care. 2014 JanMar;25(1):43-55. doi: 10.1097/ NCI.0000000000000006

Ez elarab, H, El Salam, S, Behalik, S and Eltayeb, H. (2012). Nurses ، practice, knowledge and attitude towards evidence-based practice at Yanbu general hospital-Kingdom of Saudi Arabia. Life Science Journal, $\quad$ 9, 1062- 1071.http://www.lifesciencesite.co

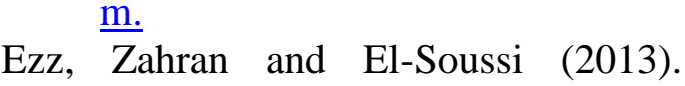
Limitations and Opportunities to research utilization in critical care settings. Journal of American Science · (ISSN: 0373-2525) (2013)Volume 3(1):PP 64-73

Hassan, W. (2016). Knowledge, attitude, beliefs, perceived barriers and implementation of evidencebased practice among pediatric nurses. SMU Medical Journal, 3(2): 60 - 77.

Hussein, A and Hussein,R. (2014). Nursing Educators' Knowledge, Skills in Evidence-Based Practice and their Critical Thinking Skills: Self Report Study. Journal of Education and Practice.ISSN 2222-1735 (Paper) ISSN 2222288X (Online) Vol.5, No.27, 2014.

Maaskant, J, Knops, A, Ubbink, D and Vermeulen, H. (2013). EvidenceBased Practice: A Survey among Pediatric Nurses and Pediatricians. Journal of Pediatric Nursing, 28(2), $\quad$ 150-157. https://doi.org/10.1016/j. outlook. 2010.06.002.

Melnyk, B and Fineout-Overholt, E. (2015).Evidence-based practice in nursing \& healthcare: A guide to best practice. (3rd ed.). Philadelphia, PA: Wolters Kluwer Health. pp. 10-16. ISBN 978-14511-9094-6.

Mohsen, M, Safaan, N, and Okby, O.(2016). Nurses' Perceptions and Barriers for Adoption of Evidence Based Practice In Primary Care: Bridging the Gap. American Journal of Nursing Research, 4(2), 25-33.

Prevost, S. and Salyer, S. (2010). In Huston, C (2010). Professional Issues in Nursing: Challenges and Opportunities (2nd ed). 
Philadelphia: Lippincott, Williams, \& Wilkins

Pryse, Y. (2012). Using evidence based practice: the relationship between work environment, nursing leadership and nurses at the bedside. Published doctorate thesis .School of Nursing, Indiana University.Published online 2012 Jul 4. doi: 10.1186/1748-5908-761

Shazly, M, Abdel- Azeem, $\mathrm{H}$ and Ahmed,N.(2018). Nurses' Beliefs and Barriers toward Evidence Based Practice. Egyptian Journal of Health Care, 2018 EJHC Vol.9 No. 2

Shifaza, F, Evans, D, and Bradley, H. (2014). nurses' perception of barriers and facilitators to implement EBP in the Maldives. Advances in nursing. Hindawi Publishing Corporation Advances in Nursing Volume 2014, Article ID 698604, 7 pages http://dx.doi.org/10.1155/2014/69 8604

Squires, A. (2017). Evidence-based approaches to breaking down language barriers. Nursing. 2017 Sep;47(9):34-40. doi: 10.1097/01.NURSE. 000052 2002. 60278.ca.

Stevens, K. (2013). The impact of evidence-based practice in nursing and the next big ideas. Online Journal of Issues in Nursing, 18(2), Manuscript 4. doi:10.3912/OJIN.Vol18No02Ma n04

Stokke, K, Olsen, N, Espehaug, B and Nortvedt, M. (2014). Evidence based practice beliefs and implementation among nurses: A cross-sectional study. BMC Nursing, 13:8.1.

Varaei S, Salsali M, Cheraghi MA. Implementation of evidence-based nursing practice for diabetic patients: An Iranian experience.
Int J Nurs Pract 2013;19(S3):7380.

http://dx.doi.org/10.1111/ijn.1217 $\underline{0}$

Williams, B, Perillo, S and Brown, T.(2015). What are the factors of organizational culture in health care settings that act as barriers to the implementation of evidencebased practice? A scoping review. Nurse Educ Today 2015;35(2):3441.

http://dx.doi.org/10.1016/j.nedt.20 $\underline{14.11 .01}$ 